\title{
Analyses of Novel Prognostic Factors in Neuroblastoma Patients
}

\author{
Susumu Ootsuka, ${ }^{a, b}$ Satoru Asami, ${ }^{a}$ Takae SAsaki, ${ }^{a}$ Yoshikazu Yoshida, ${ }^{b}$ Norimichi Nemoto, ${ }^{c}$ \\ Hiroyuki Shichino, ${ }^{d}$ Motoaki Chin, ${ }^{d}$ Hideo Mugishima, ${ }^{d}$ and Takashi Suzuki ${ }^{*, a, d}$ \\ ${ }^{a}$ Research Unit of Clinical Medicine, College of Pharmacy, Nihon University; 7-7-1 Narashinodai, Funabashi-shi, Chiba \\ 274-8555, Japan: ${ }^{b}$ Department of Hospital Pharmacy, School of Medicine, Nihon University; ${ }^{c}$ Department of Pathology, \\ School of Medicine, Nihon University; and ${ }^{d}$ Department of Pediatrics and Child Health, School of Medicine, Nihon \\ University; 30-1 Oyaguchikami-cho, Itabashi-ku, Tokyo 173-0032, Japan.
}

Received August 4, 2007; accepted September 27, 2007; published online October 1, 2007

\begin{abstract}
Neuroblastoma (NB) is the most common malignant solid tumor in childhood. There are well-recognized prognostic factors in NB such as age at diagnosis, organ of origin, stages, $M Y C N$ gene amplification, and expression of H-ras, trkA and survivin. Moreover, we investigated the expression of vascular endothelial growth factor (VEGF), tyrosine hydroxylase (TH), p53, stem cell factor (SCF) and c-kit of its receptor with quantitative realtime polymerase chain reaction (PCR) in $22 \mathrm{NBs}$ and 4 other tumors (one malignant lymphoma, one malignant teratoma, and 2 rhabdomyosarcomas) samples. The correlation between patients' prognoses and the expression of TH or c-kit was newly recognized, particularly the good prognosis in patients in whom c-kit highly expressed and the poor prognosis contrarily associated with low or no expression, although the SCF of its ligand had no relationship with patient prognosis. It is possible that tumors without c-kit expression can not react with SCF (via the autocrine or paracrine system) and remain immature. It may be that this is a new critical clinical event in NB patients.
\end{abstract}

Key words neuroblastoma; tyrosine hydroxylase; stem cell factor; c-kit

The neuroblastoma (NB) is the most common malignant pediatric solid tumor, which originates in the sympathetic nervous system and the adrenal gland. Many studies have demonstrated that both clinical and molecular biological factors are correlated with outcome. ${ }^{1)}$ For example, patients under the age of 1 year at diagnosis usually have good prognoses, but those diagnosed over 1 year of age have poor prognoses. ${ }^{2}$ Increased/decreased expression of the molecular factors, $M Y C N$, H-ras, and trkA is well known in NB. ${ }^{3-11)}$

A large body of basic research into genes and oncogenes has accumulated up till the present. Survivin has recently been described as a member of the inhibitor of apoptosis protein (IAP) family. ${ }^{12)}$ It is expressed in many malignant tumors, including breast, lung, stomach, colon and pancreatic cancers, bladder tumors, malignant lymphomas, osteosarcomas and NBs. ${ }^{13,14)}$ NBs are also characterized by elevated levels of catecholamine production. Tyrosine hydroxylase (TH) is very important as the first and rate-limiting step in the synthesis of catecholamines. ${ }^{15-18)}$ Moreover, we analyzed the following three items: vascular endothelial growth factor (VEGF), which is concerned with tumor angiogenesis and tumor metastasis together with its receptors (VEGF-Rs), ${ }^{19,20)}$ p53 (tumor suppressor gene) ${ }^{21)}$; and stem cell factor (SCF) as function of multipotent hematopoietic colony-stimulating factor (CSF) and its receptor (c-kit), based on tyrosine kinase activity. ${ }^{22,23)}$ The present study into the expression of these genes demonstrates in particular that the degree of expression of TH and c-kit mRNA is a very useful prognostic indicator.

\section{MATERIALS AND METHODS}

Patients and Tumor Samples Between 1990 and 2004 in the Department of Pediatrics and Child Health, School of Medicine, Nihon University, 26 clinical tumor samples from 26 patients (22 neuroblastomas [NBs], one malignant lym- phoma [ML], one malignant teratoma [MT], and 2 rhabdomyosarcomas [RMSs]) were examined. The clinical and pathological characteristics of these patients are shown in Table 1. The 22 NB patients consisted of 8 males and 14 females, with a mean age of 2.9 years (range 0.4 to 10.6 years), 2 cases at stage I, 6 cases at stage II, 3 cases at stage III, 10 cases at stage IV, and 1 case at stage IVS. One of the two RMS samples was from a recurrent tumor. These tissues had been stored at $-80^{\circ} \mathrm{C}$ since collection. The clinical diagnoses for these patients were histopathologically confirmed. Written informed consent was obtained from all patients before they entered this study. The study underwent ethical review and approval according to the guidelines of institutional review board (IRB) at College of Pharmacy, Nihon University.

RNA Extraction Total RNA from the 22 NBs and the 4 other malignant tumor samples was extracted with $\mathrm{TRI}_{\mathrm{ZOL}}$ reagent (Gibco BAL) by the acid-guanidium-phenol chloroform extraction method. ${ }^{24)}$

Quantitative Real-Time PCR and Gene Expression Total RNA from each tumor was reverse transcribed to cDNA using the Takara RNA PCR kit (AMV) Version 3.0 (Takara, Otsu, Japan) with oligo-dT as a primer (Table 2). Quantitative real-time PCR was carried out to detect hGAPDH expression that was used to normalize the amount of cDNA of each sample. Equal amounts of cDNA from each sample were amplified using each primers to detect (the primers sequences are listed in Table 2). This experiment was carried out with a Smart Cycler II System with Sybr green fluorochrome. The cycling conditions were as follows: initial denaturation at $95^{\circ} \mathrm{C}$ for $10 \mathrm{~s}$, followed by 40 cycles at $95^{\circ} \mathrm{C}$ for $5 \mathrm{~s}$, and $60^{\circ} \mathrm{C}$ for $20 \mathrm{~s}$. The degree of expression on each trkA, survivin (transcript variant 1), VEGF (VEGF-A), p53, $\mathrm{TH}$, SCF, and c-kit was shown as the ratio of each gene/human glyceraldehyde-3-phosphate dehydrogenase (hGAPDH) (Figs. 1-7). 
Table 1. Clinical Characteristics and Behavior in Malignant Tumor Patients

\begin{tabular}{|c|c|c|c|c|c|c|c|}
\hline Patient & Histology $^{a}$ & Stage & Sex & Age & Origin & $M Y C N \mathrm{amp}^{b)}$ & Outcome \\
\hline 1 & NB & I & $\mathrm{F}$ & $7 \mathrm{~m}$ & Adrenal gland & $\mathrm{ND}^{c)}$ & Alive \\
\hline 2 & NB & I & $\mathrm{F}$ & $1 \mathrm{y} 11 \mathrm{~m}$ & Retroperitoneum & $(-)$ & Alive \\
\hline 3 & NB & II & $\mathrm{F}$ & $9 \mathrm{~m}$ & Retroperitoneum & $(-)$ & Alive \\
\hline 4 & NB & II & $\mathrm{F}$ & $6 \mathrm{~m}$ & Retroperitoneum & $(-)$ & Alive \\
\hline 5 & NB & II & $\mathrm{F}$ & $10 \mathrm{~m}$ & Retroperitoneum & ND & Alive \\
\hline 6 & NB & II & $\mathrm{F}$ & $11 \mathrm{~m}$ & Mediastinum & ND & Alive \\
\hline 7 & NB & II & M & $7 \mathrm{~m}$ & Adrenal gland & ND & Alive \\
\hline 8 & NB & II & $\mathrm{F}$ & $9 \mathrm{~m}$ & Adrenal gland & $(+)$ & Alive \\
\hline 9 & NB & III & $\mathrm{F}$ & $6 y$ & Adrenal gland & $(-)$ & Alive \\
\hline 10 & NB & III & $\mathrm{F}$ & $8 \mathrm{~m}$ & Retroperitoneum & $(-)$ & Alive \\
\hline 11 & NB & III & M & $4 \mathrm{~m}$ & Adrenal gland & ND & Alive \\
\hline 12 & NB & IV & $\mathrm{F}$ & $1 \mathrm{y}$ & Mediastinum & ND & Alive \\
\hline 13 & NB & IV & $\mathrm{F}$ & $2 y$ & Adrenal gland & $(-)$ & Dead \\
\hline 14 & NB & IV & M & 4 y $11 \mathrm{~m}$ & Adrenal gland & $(-)$ & Dead \\
\hline 15 & NB & IV & M & $5 \mathrm{y} 9 \mathrm{~m}$ & Adrenal gland & ND & Dead \\
\hline 16 & NB & IV & $\mathrm{F}$ & 10 y $7 \mathrm{~m}$ & Adrenal gland & $(-)$ & Dead \\
\hline 17 & NB & IV & M & $3 y$ & Retroperitoneum & $(-)$ & Alive \\
\hline 18 & NB & IV & M & $3 y$ & Adrenal gland & ND & Dead \\
\hline 19 & NB & IV & $\mathrm{F}$ & $4 \mathrm{y} 4 \mathrm{~m}$ & Adrenal gland & $(-)$ & Alive \\
\hline 20 & NB & IV & M & 3 y $3 \mathrm{~m}$ & Adrenal gland & $(+)$ & Dead \\
\hline 21 & NB & IV & $\mathrm{M}$ & 9 y $6 \mathrm{~m}$ & Adrenal gland & $(-)$ & Alive \\
\hline 22 & NB & IVS & $\mathrm{F}$ & $7 \mathrm{~m}$ & Adrenal gland & $(-)$ & Alive \\
\hline 23 & ML & & $\mathrm{F}$ & $7 y$ & & & \\
\hline 24 & MT & & $\mathrm{F}$ & $17 \mathrm{y}$ & & & \\
\hline 25 & RMS & & $\mathrm{F}$ & Unknown & & & \\
\hline 26 & RMS & & M & $15 \mathrm{y}$ & & & \\
\hline
\end{tabular}

a) NB: neuroblastoma, ML: malignant lymphoma, MT: malignant teratoma, RMS: rhabdomyosarcoma. $\quad b)$ MYCN amp: $M Y C N$ amplification. $\quad c$ ) N.D.: not done.

Table 2. Primers Used for PCR

\begin{tabular}{llc}
\hline \hline \multicolumn{1}{c}{ Genes } & \multicolumn{1}{c}{ Primer sequence } & Size (bases) \\
\hline \multirow{2}{*}{ trkA } & F: 5'-TTGGCATGAGCAGGGATATCTACA-3' & \multirow{2}{*}{117} \\
& R: 5'-TCTCGGTGGTGAACTTACGGTACA-3' & \\
\multirow{2}{*}{ Survivin } & F: 5'-AAGGCTGGGAGCCAGATGAC-3' & 63 \\
& R: 5'-AAGCGCAACCGGACGAAT-3' & \multirow{2}{*}{148} \\
VEGF & F: 5'-GAGCCTTGCCTTGCTGCTCTAC-3' & \\
& R: 5'-CACCAGGGTCTCGATTGGATG-3' & 123 \\
p53 & F: 5'-TGCCCAACAAACCAGCTC-3' & \multirow{2}{*}{165} \\
& R: 5'-CCAAGGCCTCATTCAGCTCTC-3' & \multirow{2}{*}{166} \\
TH & F: 5'-GGAGTTCGGGCTGTGTAAGCA-3' & \multirow{2}{*}{113} \\
& R: 5'-GACTGGTACGTCTGGTCTTGGTAGG-3' & \\
& F: 5'-CCCTTAGGAATGACAGCAGTAGCA-3' & \\
& R: 5'-GCCCTTGTAAGACTTGGCTGTCTC-3' & \\
& F: 5'-AGGATTCCCAGAGCCCACAATAG-3' & \\
& R: 5'-ACGGTGGCCCAGATGAGTTTAG-3' &
\end{tabular}

Statistical Analysis All statistical analyses were performed using GraphPad Prism 4 (Graphpad, San Diego, CA, U.S.A.). Data were expressed as means \pm standard deviation. Mean values of continuous variables were compared using analysis of variance (ANOVA) and did Tukey's test after transforming the data to logarithmic values. The significance level was set at $p$-values equal to or less than 0.05 .

\section{RESULTS AND DISCUSSION}

Advanced NBs are the most malignant pediatric solid tumors, patients suffering from which have poor prognoses, so it is important to identify patients with unfavorable outcomes for whom we can then select appropriately strong chemotherapeutic regimes. Moreover, we can also improve the prognoses of these patients.
We examined 26 malignant tumor samples including the $22 \mathrm{NBs}$ and four other tumors (one ML, one MT, and 2 RMSs (one is a recurrent case)). The clinical characteristics and behavior of the 22 NB patients in particular are shown in Table 1. As for staging, stages I, II, III, and IV accounted for $2,6,3$, and 11 , respectively, and 1 was a special case at stage IVS. It has been generally recognized that stage I, II, and IVS (special stage IV with favorable outcome) patients have good prognoses and stage III, and IV (so called "advanced NB") have poor prognoses. ${ }^{1-3,25)}$ Regarding gender and age at diagnosis, 8 cases were males and 14 cases females, with a mean age of 2.9 years (range 0.4 to 10.6 years). It has been reported that patients younger than 1 year old have a much more favorable outcome than older patients. ${ }^{1-3,25)}$ The organs of origin were the retroperitoneum in 6 , the adrenal gland in 14 and the mediastinum in 2 cases (in general, NBs of adrenal gland origin have poor prognoses). ${ }^{1-3,25)} \mathrm{MYCN}$ gene amplification is very much related to patient prognosis and was recognized only each of the stage II and stage IV patients. As for patient outcome, all patients at stages I, II, III, and VIS are alive, on the contrary, 5 of the 11 stage IV patients are alive and 6 have died.

We measured some genes expressions (trkA, survivin, VEGF, p53, TH, SCF, and c-kit) in the NB clinical samples with quantitative real-time PCR. Moreover, we quantified individual gene expression among the $22 \mathrm{NBs}$ and 4 other tumor samples; among the stage I, II, and IVS (early stages) samples and stage III and IV (advanced stages) samples; and between patients who survived and died.

TrkA is a nerve growth factor (NGF) receptor, which plays an important role in the growth and differentiating of neural cells. It has been reported that having little or none of this gene expression is a critical event and is related to the prog- 
A

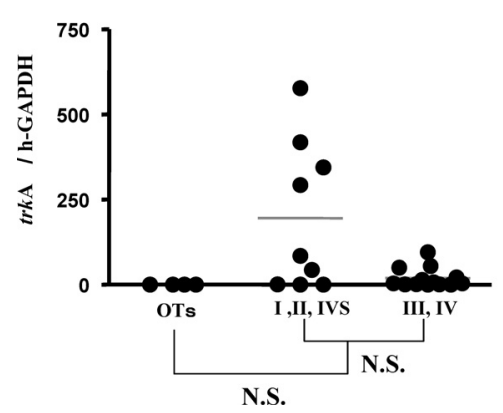

B

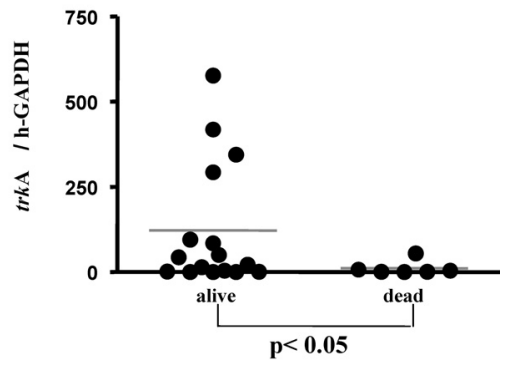

Fig. 1. The Expression of trkA mRNA in 26 Malignant Tumor Samples

(A) We classified 26 samples into 2 different groups: 22 NBs and 4 other malignant tumors (OTs: one malignant lymphoma [ML], one malignant teratoma [MT], and 2 rhabdomyosarcomas [RMSs]); stages I, II, and IVS (early stages), and satges III and IV (advanced stages). We performed statistical analyses among the 22 NBs and 4 OTs and among the early and advanced stages (as above) in $22 \mathrm{NBs}$ for the degree of trkA expression (relative to h-GAPDH as the internal marker). (B) In addition to the 2 groups detailed above, performed a statistical analysis between surviving and dead NB patients by the same method. The lines in the figure represent the median. N.S.: not significant, $p$ : $p$-value $(<0.05)$.

A

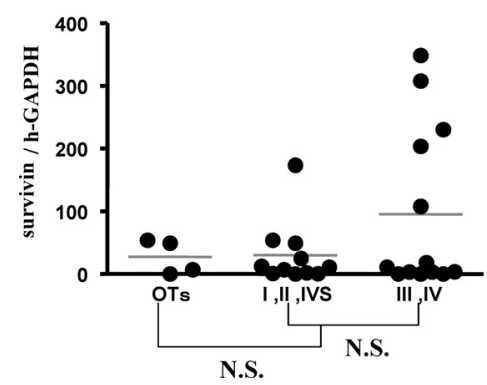

B

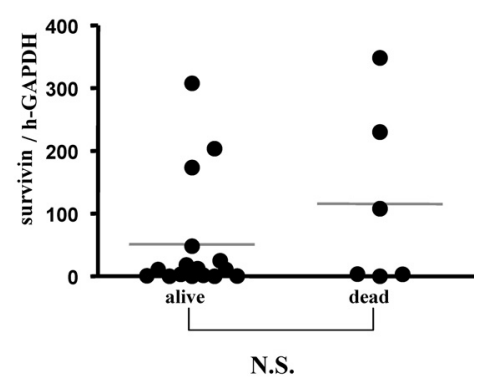

Fig. 2. The Expression of Survivin mRNA in 26 Malignant Tumor Samples

(A) Statistical analyis among the $22 \mathrm{NBs}$ and 4 OTs and among early and advanced stages in $22 \mathrm{NBs}$ for the degree of survivin expression (relative to h-GAPDH as the internal marker). (B) Statistical analysis using the same method between surviving and dead NB patients. The lines in the figure represent the median. N.S.: not significant.

nosis for NB patients. ${ }^{7-9)}$ Although the expression of trkA was not statistically significant among the $22 \mathrm{NBs}$ and 4 other malignant tumors (OTs), and among the early stages (stage I, II, IVS) and advanced stages (stage III, IV) samples, it was, however, statistically significant between the surviving patients and those who died $(p<0.05)$ (Fig. 1). This means that the existence of high or low trkA expression is also a good prognostic factor in NB patients as many researchers have reported. ${ }^{7-9)}$

Survivin is abundantly expressed during fetal development but not in adult human tissues. ${ }^{26)}$ We have previously suggested that it is an important prognostic factor in NB (14 cases) and osteosarcoma patients (22 cases). ${ }^{27,28)}$ However, in the larger number of $22 \mathrm{NB}$ cases in the present study we could not find any difference among the 22 NBs and 4 OTs, the early stages (stage I, II, IVS) and advanced stages (stage III, IV), and between surviving and dead patients (Fig. 2). Although survivin mRNA has been detected in various human cancers, ${ }^{29,30)}$ the lack of statistical significance in our 22 NB cases is possibly due to the low number of patients who died (6) compared with those who survived (12).

Vascular endothelial growth factor (VEGF), together with its receptors (VEGF-Rs), is concerned with tumor angiogenesis and tumor metastasis. ${ }^{19,20)}$ However, the correlation between prognosis and VEGF mRNA expression levels has not been evaluated based on surgically resected samples. Recently it has been reported in a phase III trial that the combi- nation of bevacizumab (a human VEGF antibody) with irinotecan, fluorouracil, and leucovorin was very effective for advanced metastatic colorectal cancer patients. ${ }^{31)}$ We therefore investigated the expression of VEGF (VEGF-A) mRNA in our 26 tumor samples, but were unable to see any statistically significant differences in the three groups we compared (22 NBs and 4 OTs, early and advanced stages, and surviving and dead NB patients) (Fig. 3). This means that the level of VEGF-A mRNA have no prognostic correlation for NBs, but it may be an important target protein to treat advanced NB patients.

p53 is termed the "tumor suppressor gene," and gene alteration of more than $50 \%$ (that is loss or point mutation on specific DNA binding region) has been found in various tumors. ${ }^{32,33)}$ This alteration of p53 is concerned with resistance to radiation and anti-tumor drugs. ${ }^{34,35)}$ We therefore analyzed the expression of the p53 gene, but once again no statistically significances could be seen in the three groups we compared (Fig. 4). It is possible that p53 has no prognostic correlation in NB patients because no p53 gene mutation has been found in NB surgical samples. ${ }^{36}$ )

$\mathrm{TH}$ is very important as the first and rate-limiting step in the synthesis of catecholamines, and NB is characterized by elevated levels of catecholamine production. ${ }^{15-18)}$ We investigated the 26 clinical tumor samples with the same method. We found that TH mRNA was much higher expressed in the NB samples than the OTs. Moreover, in the surviving NB pa- 
A

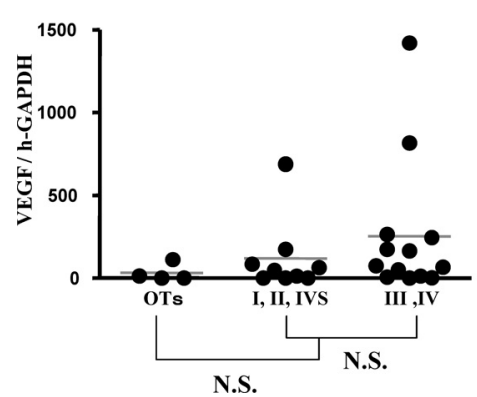

B

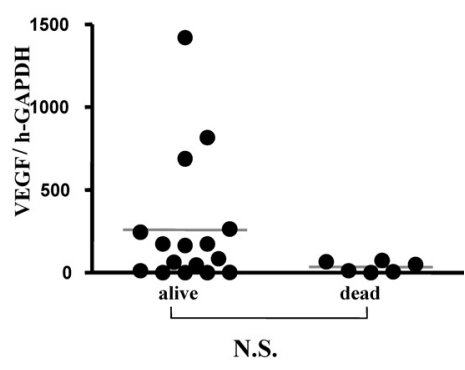

Fig. 3. The Expression of Vascular Endothelial Growth Factor (VEGF-A) mRNA in 26 Malignant Tumor Samples

(A) Statistical analysis among the 22 NBs and 4 OTs and among the early and advanced stages in 22 NBs for the degree of VEGF-A expression (relative to h-GAPDH as the internal marker). (B) Statistically analysis using the same method between surviving and dead NB patients. The lines in the figure represent the median. N.S.: not significant.

A

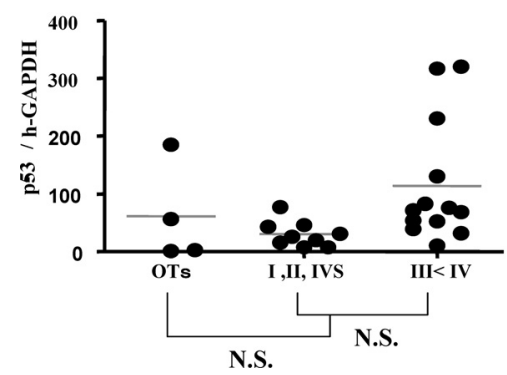

B

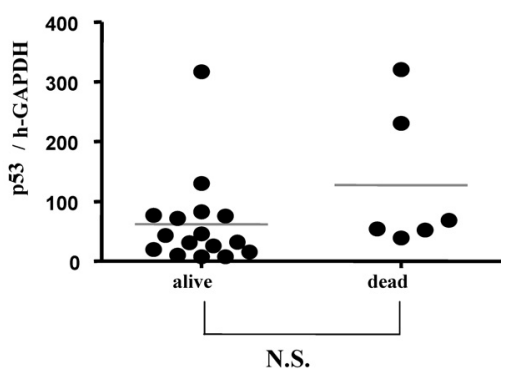

Fig. 4. The Expression of p53 mRNA in 26 Malignant Tumor Samples

(A) Statistical analysis among the $22 \mathrm{NBs}$ and 4 OTs and among the early and advanced stages in 22 NBs for the degree of p53 expression (relative to h-GAPDH as the internal marker). (B) Statistical analysis using the same method between surviving and dead NB patients. The lines in the figure represent the median. N.S.: not significant.

A

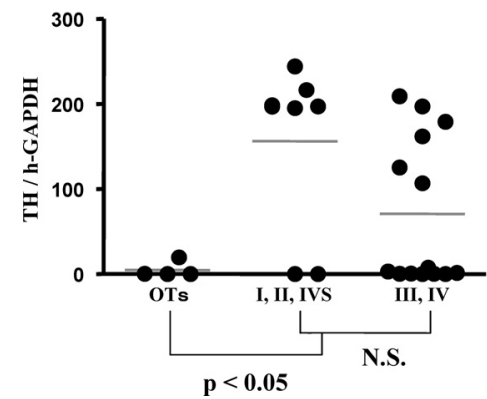

B

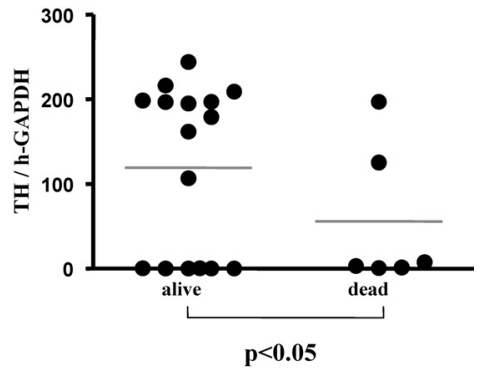

Fig. 5. The Expression of Tyrosine Hydroxylase (TH) mRNA in 26 Malignant Tumor Samples

(A) Statistically analysis among the 22 NBs and 4 OTs and among the early and advanced stages in 22 NBs for the degree of VEGF expression (relative to h-GAPDH as the internal marker). (B) In addition to the 2 groups detailed above, we performed a statistical analysis between surviving and dead NB patients by the same method. The lines in the figure represent the median. N.S.: not significant, $p$ : $p$-value $(<0.05)$.

tients it was also much higher than in those who had died. This is very useful for diagnosing NB and detecting minimal residual disease in clinical bone marrow (BM) samples and autologous BM and peripheral blood stem cell samples. Moreover, we could also use TH expression in assessing the prognosis of NB patients (Fig. 5).

Stem cell factor (SCF) is a function of the multipotent hematopoietic colony-stimulating factor (CSF). SCF exerts its biological effects by binding to the tyrosine kinase receptor c-Kit, which is located on the cell surface. ${ }^{22,23,37)}$ Signal transduction by this receptor plays a critical role in hematopoiesis, in mast cell development and function, and in development of melanocytes and germ cells. It has also been demonstrated that this ligand-receptor pair has an anti-apoptosis effect on primordial germ cells. ${ }^{38)}$ Neuroblastic tumors (including NB, ganglioneuroblastoma, and ganglioma) are also derived from the primordial neural crest cells, that ultimately populate the sympathetic ganglia and adrenal medulla. The variations in tumor locations and degrees of histopathologic differentiation result in an array of diverse clinical and biological characteristics and behavior. ${ }^{25}$ )

We investigated the expression of SCF and its receptor (ckit) in clinical NB tumor samples. No statistically significance was observed regarding SCF expression among the 22 
A

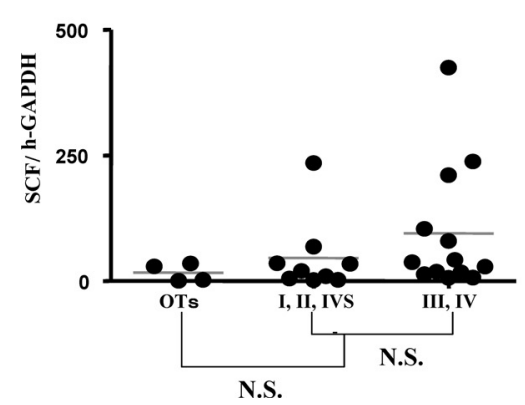

B

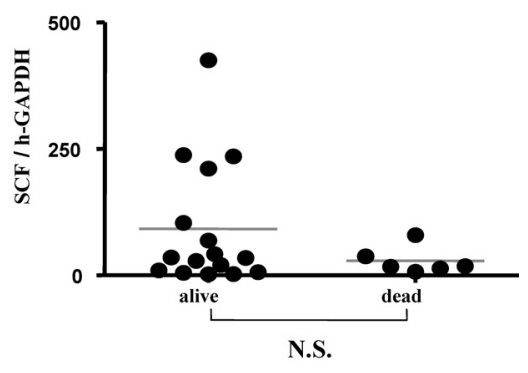

Fig. 6. The Expression of Stem Cell Factor (SCF) mRNA in 26 Malignant Tumor Samples

(A) Statistical analysis among the 22 NBs and 4 OTs and among the early and advanced stages in 22 NBs for the degree of SCF expression (relative to h-GAPDH as the internal marker). (B) Statistical analysis using the same method between surviving and dead NB patients. The lines in the figure represent median. N.S.: not significant.

A

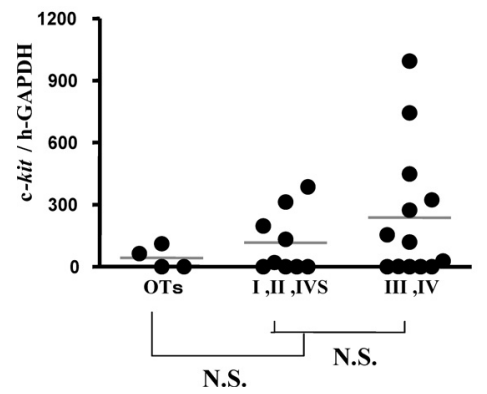

B

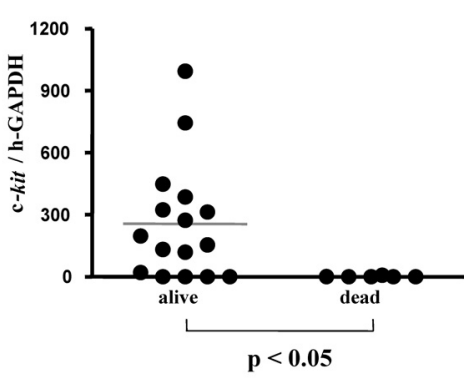

Fig. 7. The Expression of c-kit mRNA in 26 Malignant Tumor Samples

(A) Statistical analysis among the 22 NBs and 4 OTs and among the early and advanced stages in 22 NBs for the degree of c-kit expression (relative to h-GAPDH as the internal marker). (B) In addition to the 2 groups detailed above, we performed a statistical analysis between surviving and dead NB patients by the same method. The lines in the figure represent median. N.S.: not significant, $p$ : $p$-value $(<0.05)$.

NBs and 4 OTs, The early or advanced stage specimens or between the surviving and dead NB patients (Fig. 6). In c-kit expression, on the other hand, statistical significance was found between the surviving and dead NB patients $(p<0.05)$ (Fig. 7). Based on these findings, the level of c-kit expression is not useful for diagnosing NB or detecting minimal residual disease as is the case with TH, but it could be a useful prognostic factor in NB patients.

It has been reported that autocrine growth in various tumors (gynecological tumors, small cell lung cancer, and pancreatic cancer) is mediated by the coexpression of SCF and c-kit. ${ }^{39-41)}$ Moreover, one report has said that NB tumors which have been immunohistochemically confirmed as being c-Kit or SCF protein positive have an unfavorable histology and the c-kit receptor becomes an important clinical therapeutic target. ${ }^{42)}$ On the contrary, another report stated that cKit positive NBs have favorable prognoses based on the same immunohistochemical method. ${ }^{43}$ Based on our findings, although the SCF mRNA expression had no prognostic value for our NB patients, surviving NB patients had high expression of c-kit mRNA compared with little or no c-kit expression in the NB patients who subsequently died. It is possible that NB tumor cells with c-kit expression-positive NB tumor cells can react with SCF (by autocrine or paracrine system), but tumor cells with no such expression can not react, and these tumors continue to be immature. This might well be a new critical clinical event in NB patients.
Acknowledgements This work was supported in part by the "Academic Frontier" Project for Private Universities: matching fund subsidy from MEXT (Ministry of Education, Culture, Sports, Science and Technology) 2007-2010.

\section{REFERECES}

1) Brodeur G. M., Eur. J. Cancer, 31, 505-510 (1995).

2) Sawada T., Hirayama M., Nakata T., Takeda T., Takasugi N., Mori T., Maeda K., Koide R., Hanawa Y., Tsunoda A., Lancet, 2, 271-273 (1984).

3) Bordow S. B., Norris M. D., Haber P. S., Marshall G. M., Haber M., J. Clin. Oncol., 16, 3286-3294 (1998).

4) Brodeur G. M., Seeger R. C., Schwab M., Varmus H. E., Bishop J. M., Science, 224, 1121-1124 (1984).

5) Seeger R. C., Brodeur G. M., Sather H., Dalton A., Siegel S. E., Wong K. Y., Hammond D., N. Engl. J. Med., 313, 1111-1116 (1985).

6) Matsunaga T., Takahashi H., Ohnuma N., Tanabe M., Yoshida H., Iwai J., Shirasawa H., Shimizu B., Cancer Res., 51, 3148-3152 (1991).

7) Nakagawawa A., Nakagawara-Arima M., Scarvarda N. J., Azar C. G., Cantor A. B., Brodeur G. M., N. Engl. J. Med., 328, 847-854 (1993).

8) Suzuki T., Bogenmann E., Shimada H., Starm D., Seeger R., J. Natl. Cancer Inst., 85, 377-384 (1993).

9) Kogner P., Barbany G., Dominici C., Castello M. A., Raschella G., Persson H., Cancer Res., 53, 2044-2050 (1993).

10) Tanaka T., Sugimoto T., Sawada T., Cancer, 83, 1626-1633 (1993).

11) Matsunaga T., Shirasawa H., Enomoto H., Yoshida H., Iwai J., Tanabe M., Kawamura K., Etoh T., Ohnuma N., Int. J. Cancer, 79, 226-231 (1998).

12) Ambrosini G., Adida C., Altieri D. C., Nature Medicine, 3, 917-921 (1997).

13) Nasu S., Yagihashi A., Izawa A., Saito K., Asanuma K., Nakamura M., 
Kobayashi D., Okazaki M., Watanabe N., Anticancer Res., 22, 18391844 (2002)

14) Osaka E., Suzuki T., Osaka S., Yoshida Y., Sugita H., Asami S., Tabata K., Sugitani M., Nemoto N., Ryu J., J. Orhtopaed. Res., 116-121 (2007)

15) Nagatsu T., Cell. Mol. Neurobiol., 9, 313-321 (1989).

16) Reynolds C. P., Seeger R. C., "Cancer Treatment, Part Neuroblastoma," ed. by Haskell C. M., Sanders, Philadelphia, 1995, pp. 860871.

17) Reynolds C. P., Biedler J. L., Spengler B. A., Reynolds D. A., Ross R. A., Frenkel E. P., Smith R. G., J. Natl. Cancer Inst., 76, 375-387 (1986).

18) Grima B., LAmouroux A., Boni C., Julien J. F., Javoy-Agid F., Mallet J., Nature (London), 326, 707-711 (1987).

19) Shibuya M., Claesson-Welsh L., Exp. Cell Res., 312, 549-560 (2006)

20) Kaplan R. N., Riba R. D., Zacharoulis S., Bramley A. H., Vincent L., Costa C., MacDonald D. D., Jin D. K., Shido K., Kerns S. A., Zhu Z., Hicklin D., Wu Y., Port J. L., Altorki N., Port E. R., Ruggero D., Shmelkov S. V., Jensen K. K., Rafii S., Lyden D., Nature (London), 438, 820-827 (2005).

21) Finlay C. A., Hinds P. W., Levine A. J., Cell, 57, 1083-1093 (1989).

22) Zsebo K., Williams D., Geissler E., Brroudy V., Martin F., Atkins H., Hsu R.-Y., Birkett N., Okino K., Murdock D., Jacobson F., Langley K., Smith K., Takeishi T., Cattanach B., Galli S., Suggs S., Cell, 63, 213224 (1990).

23) Yarden Y., Kuang W.-J., Yang-Feng T., Coussens L., Munemitsu S., Dull T. J., Chen E., Schlessinger J., Francke U., Ullrich A., EMBO J., 6, 3341-3351 (1987).

24) Piotr C., Nicoletta S., Anal. Biochem., 162, 156-159 (1987).

25) Pizzo P. A., Poplack D. G., "Principles and Practice of Pediatric Oncology," 4th ed., Lippincott Williams \& Wilkins, Philadelphia, 2002, pp. $895-937$.

26) Ambrosini G., Adida C., Altieri D. C., Nat. Med., 3, 917-921 (1997).

27) Ito R., Asami S., Motohashi S., Ootsuka S., Yamaguchi Y., Chin M., Shichino H., Yoshida Y., Nemoto N., Mugishima H., Suzuki T., Biol. Pharm. Bull., 28, 565-568 (2005).

28) Osaka E., Suzuki T., Osaka S., Yoshida Y., Sugitani H., Asami S., Tabata K., Hemmi A., Sugitani M., Nemoto N., Ryu J., J. Orthopaed. Res., 39, 95-100 (2006).
29) Span P. N., Sweep F. C. Wiegerinck E. T., Clin. Chem., 50, 19861993 (2004).

30) Wang H., Xi X., Kong X., J. Cancer Res. Clin. Oncol., 130, 487-490 (2004).

31) Hurwit H., Ferenbacher L., Novatny W., Cartwright T., Hainsworth J., Heim W., Berlin J., Baron A., Griffings S., Holmgren E., Ferrara N., Fyfe G., Rogers B., Ross R., Kabbinavar F., N. Engl. J. Med., 350, 2335-2342 (2004).

32) Nigro J. M., Baker S., Presinger A. C., Jessup J. M., Hosteller R., Cleary K., Singer S. H., Davidson N., Baylin S., Devilee P., Glover T., Collins F. S., Weslon A., Modali R., Harris C. C., Vogelstein B., Nature (London), 342, 705-708 (1989).

33) Takahashi T., Nau M. M., Chiba I., Birrer M. J., Rosenberg R. K., Vinocour M., Levitt M., Pass H., Gazdar A. F., Minna J. D., Science, 246, 491-494 (1989).

34) Lee J. M., Bernstein A., Proc. Natl. Acad. Sci. U.S.A., 90, 5742-5746 (1993).

35) Wattel E., Preudhome C., Hecque B., Vanrumbeke M., Quesnel B., Dervite I., Morel P., Fenaux P., Blood, 84, 3148-3157 (1994).

36) Vogan K., Bernstein M., Leclerc J.-M., Brisson L., Brossard J., Brodeur, Pelletier J., Gros P., Cancer Res., 53, 5269-5273 (1993).

37) Pietsch T., Kyas U., Steffens U., Yakisan E., Hadam M. R., Ludwig W.-D., Zsebo K., Welte K., Blood, 80, 1199-1206 (1992).

38) Høyer P. E., Byskov A. G., Møllgard K., Mol. Cell Endocrinol., 234, $1-10$ (2005).

39) Inoue M., Kyo S., Fujita M., Enomoto T., Kondoh G., Cancer Res., 54, 3049-3053 (1994).

40) Krystal G. W., Hines S. J., Organ C. P., Cancer Res., 56, 370-376 (1996).

41) Yasuda A., Sawai H., Takahashi H., Ochi N., Matsuo Y., Funahashi H., Sato M., Okada Y., Takeyama H., Manabe T., Mol. Cancer, 5(46), 110 (2006).

42) Uccini S., Mannarino O., McDowell H. P., Pauser U., Vitali R., Natali P. G., Altavista P., Andreano T., Coco S., Boldrini R., Bosco S., Clerico A., Cozzi D., Donfrancesco A., Inserra A., Kokai G., Losty P. D., Nicotra M. R., Raschella G., Tonini G. P., Dominici C., Clin. Cancer Res., 11, 380-389 (2005).

43) Krams M., Parwaresch R., Sipos B., Heidorn K., Harms D., Rudolph P., Oncogene, 23, 588-595 (2004). 